\title{
Pulmonary B-cell non-Hodgkin's lymphoma associated with autoimmune disorders: a clinicopathological review of six cases
}

\author{
A.G. Nicholson*, A.C. Wotherspoon**, A.L. Jones+, M.N. Sheppard*, \\ P.G. Isaacson**, B. Corrin*
}

Pulmonary B-cell non-Hodgkin's lymphoma associated with autoimmune disorders: a clinicopathological review of six cases. A.G. Nicholson, A.C. Wotherspoon, A.L. Jones, M.N. Sheppard, P.G. Isaacson, B. Corrin. (CERS Journals Ltd 1996.

ABSTRACT: Because pulmonary B-cell non-Hodgkin's lymphomas are now thought to arise in bronchial mucosa-associated lymphoid tissue (MALT), 45 patients with pulmonary B-cell lymphomas were reviewed to look for aetiological factors in the lung.

It was found that six of the 45 lymphomas arose in patients with systemic autoimmune disease, which in three patients involved the lung. These three patients all had cryptogenic fibrosing alveolitis treated with long-term immunosuppressive therapy. Five of the six lymphomas were high grade and one was low grade.

The association of pulmonary lymphomas with autoimmune interstitial lung disease is consistent with associations between autoimmune diseases and lymphomas presenting at other mucosal sites, and lends weight to the hypothesis that formation of bronchial mucosa-associated lymphoid tissue precedes the development of lymphoma.

Eur Respir J., 1996, 9, 2022-2025.

Depts of Histopathology, *Royal Brompton Hospital and **University College Hospital*, and +Dept of Oncology, Royal Marsden Hospital, London, UK.

Correspondence: A.G. Nicholson

Dept of Histopathology

Royal Brompton Hospital

Sydney Street

London SW3 6NP

UK

Keywords: Autoimmune disease, lung, lymphoma, mucosa-associated lymphoid tissue

Received: November 91995

Accepted after revision June 151996
Although rare, pulmonary B-cell non-Hodgkin's lymphomas are well-recognized [1-4], with recent series suggesting that most arise in bronchial mucosa-associated lymphoid tissue (MALT) [5-9]. Such extranodal lymphomas were first described in the stomach [10], and subsequently at many other mucosal sites.

Gastric lymphomas generally arise in MALT formed through prolonged Helicobacter pylori infection [11]. MALT is also thought not to be a native constituent of the human bronchial tree, but to develop in response to various antigenic stimuli [12-15]. We therefore reviewed our cases of pulmonary lymphoma to see if there was any evidence of chronic antigenic stimulus of the pulmonary MALT preceding the development of lymphoma.

\section{Materials and methods}

Forty five extranodal pulmonary B-cell lymphomas were found in the histopathology files of the Royal Brompton
Hospital. Thirty nine were primary, and six were MALT lymphomas that developed in the lung after other presentation at mucosal sites. When the clinical details were reviewed, it was found that six patients also suffered from autoimmune disease. Their histology was reviewed using standard streptavidin-biotin immunohistochemistry with CD20 (Dako-M755, dilution 1:100) and CD3 (DakoA452, dilution 1:50) antibodies to phenotype the lymphomas. Predigestion with trypsin was required for the demonstration of CD3.

\section{Results}

The clinical details of the six patients with autoimmune disorders are presented in table 1. Four were male and two were female. Investigations on two patients for a monoclonal gammopathy and on two patients for serological evidence of Epstein-Barr virus infection were negative.

Table 1. - Clinical features of pulmonary B-cell lymphomas associated with autoimmune diseases

\begin{tabular}{llllll}
\hline $\begin{array}{l}\text { Case } \\
\text { No. }\end{array}$ & $\begin{array}{c}\text { Age } \\
\text { yrs }\end{array}$ & Sex & Previous disease & $\begin{array}{c}\text { Treatment prior to } \\
\text { diagnosis of lymphoma }\end{array}$ & Survival \\
\hline 1 & 68 & M & RA for 5 yrs & Steroids & Found at autopsy \\
2 & 68 & M & PM/CFA for 17 yrs & Steroids & Died at one week \\
3 & 43 & M & RA/CFA for 15 yrs & Steroids/AZ & Found at autopsy \\
4 & 60 & F & Mixed CTD/CFA for 17 yrs & Steroids/AZ & Died at 6 months \\
5 & 57 & F & RA for 9 yrs & Steroids/CP & Found at autopsy \\
6 & 51 & M & Sj. for 5 yrs & None & Died at 4 yrs \\
\hline
\end{tabular}

RA: rheumatoid arthritis; PM: polymyositis; CFA: cryptogenic fibrosing alveolitis; Sj.: Sjörgen's syndrome; AZ: azathioprine; CP: cyclophosphamide; CTD: connective tissue disease. 


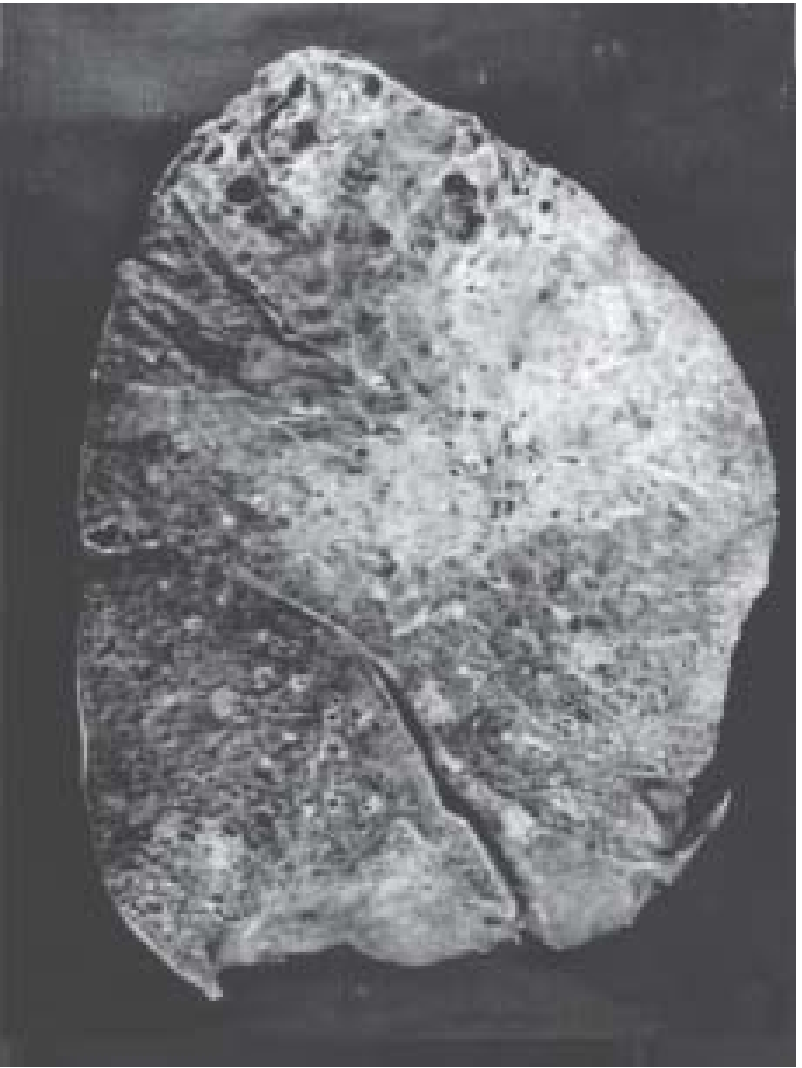

Fig. 1. - Section of whole lung at autopsy from a patient with high grade lymphoma arising on a background of fibrosing alveolitis (note honeycombing within a shrunken lower lobe).

Three had had interstitial lung disease for 15-17 yrs, their pulmonary deterioration accelerating terminally over periods ranging from 18 months to 4 years (fig. 1). These three patients all had their interstitial lung disease treated with steroids, with two receiving additional azathioprine. Two other patients had also been treated with steroids, and one of these had also received cyclophosphamide, prior to identification of their neoplasia at autopsy. These five patients all had high grade lymphomas. Case No. 6 was diagnosed as having Sjögren's syndrome 5 yrs before developing a low grade lymphoma.

The pathological features of the lymphomas are shown in table 2. Without an established method of grading pulmonary B-cell lymphomas, the principles of the updated Kiel classification were used to subdivide cases into low and high grade, mirroring the approach used to classify intestinal lymphomas [16]. Macroscopically, the lymphoma was nodular in all six cases, being multifocal in

Table 2. - Pathological features of pulmonary B-cell lymphomas associated with autoimmune diseases

\begin{tabular}{llll}
\hline $\begin{array}{l}\text { Case } \\
\text { No. }\end{array}$ & Grade* & \multicolumn{1}{c}{ Site } & \multicolumn{1}{c}{$\begin{array}{c}\text { Other sites } \\
\text { involved }\end{array}$} \\
\hline 1 & High & Bilateral & Liver, adrenal \\
2 & High & Bilateral & Hilar nodes \\
3 & High & Unilateral & None \\
4 & High & Unilateral & Bone marrow \\
5 & High & Bilateral & Spleen, liver \\
6 & Low & Unilateral & Salivary gland \\
\hline
\end{tabular}

*: lymphomas were graded as high or low according to the updated Kiel classification [16]. a)

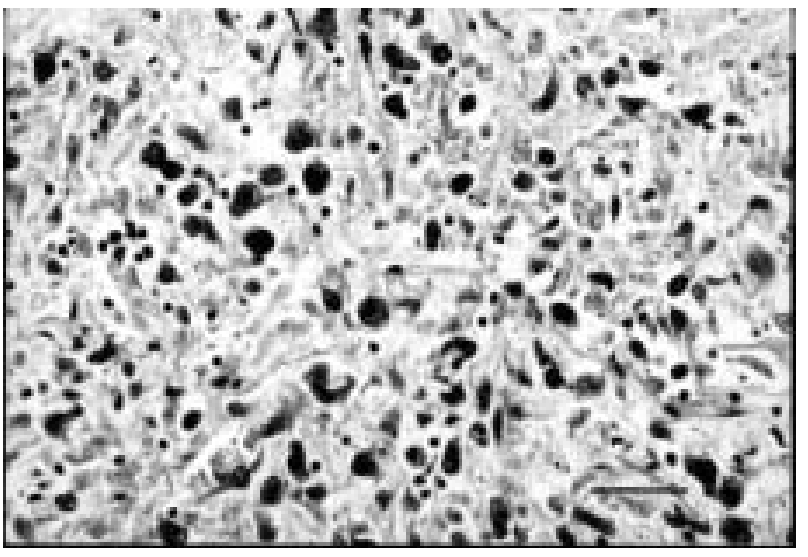

b)

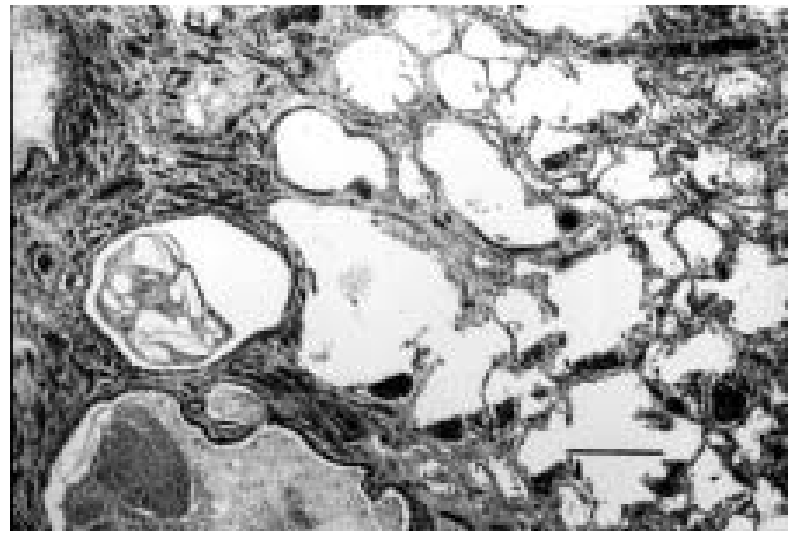

Fig. 2. - a) A diffuse infiltrate of large pleomorphic lymphoid cells which stained positively for CD20, indicating a high grade B-cell nonHodgkin's lymphoma. Scale bar $=100 \mu \mathrm{m}$. b) Cryptogenic fibrosing alveolitis from the same patient, with the characteristic histological features of patchy loss of architecture, bronchiolization of airspaces and interstitial fibrosis. Scale bar $=1 \mathrm{~mm}$.

the three bilateral cases and localized to right upper lobe, right mid-zone and right lower lobe, respectively, in the three unilateral cases. On microscopy, the five high grade cases consisted of sheets of CD20+ (B-cell marker) blast cells and necrosis, the patients with underlying cryptogenic fibrosing alveolitis having the characteristic histological features of their interstitial lung disease in areas spared by lymphoma (fig. 2). The single low grade case had the characteristic features of a low grade B-cell lymphoma of MALT origin. Bronchial MALT in lung uninvolved by tumour was not seen in any of the six cases.

Three cases were not recognized as having lymphoma until autopsy. Two of these had microscopic foci of lymphoma in other organs on microscopy. Of the two high grade cases diagnosed in life, both on fibreoptic bronchoscopic biopsy, one died 2 days after combination chemotherapy was started (Case No. 2), and the other received chlorambucil only as her overall physical condition was considered too poor to withstand aggressive chemotherapy (Case No. 4).

Case No. 6 was treated with steroids and for a short period with azathioprine after low grade lymphoma was diagnosed. He died of myocardial infarction 4 yrs later and autopsy showed that the lymphoma was limited to lung and salivary gland. 


\section{Discussion}

The majority of B-cell lymphomas of MALT origin are low grade $[6,8,9]$, although high grade tumours predominated in this particular subgroup. Although high grade disease usually lacks the histological characteristics of low grade lymphomas of MALT origin, it is welldocumented that transformation between low and high grade MALT lymphomas occurs and accounts for a significant number of high grade tumours at mucosal sites $[6,8,9,17]$. No bronchial MALT was seen in lung uninvolved by tumour in the six cases associated with autoimmune disorders, though this was a retrospective study and sampling of uninvolved lung was predominantly limited to areas of interstitial lung disease where fibrosis predominated.

Although pulmonary lymphoma has occasionally been reported in association with rheumatoid arthritis [18], the association with underlying cryptogenic fibrosing alveolitis has not previously been documented. These cases constitute a subgroup of pulmonary B-cell lymphomas that have a particularly poor prognosis compared to other series of MALT lymphomas of either low or high grade $[6,7]$. The poor survival of these patients is, perhaps, due to the combined effects of the tumour and the underlying lung disease on respiratory function.

Continuing turnover of lymphoid follicles is thought to underlie the development of nodal lymphoma in rheumatoid disease [19]. Lymphoid interstitial pneumonitis, another chronic pulmonary manifestation of rheumatoid and other autoimmune diseases, has also been associated with immunoblastic malignant transformation in the lung [20]. Therefore, it is possible that the development and chronic turnover of bronchial MALT as part of lymphoid interstitial pneumonia or cryptogenic fibrosing alveolitis, both described in patients with autoimmune diseases [21], may precede the development of these pulmonary lymphomas. However, in Case No. 6, where lymphoma was found in the salivary glands at autopsy, the possibility that it originated at this site and subsequently spread to the lungs cannot be excluded.

Rheumatoid disease is associated with an increased risk of developing lymphoma [18, 19, 22], even in those patients who are not treated with immunosuppressive therapy [23]. However, immunosuppressive therapy seems likely to be an additional factor, for lymphomas occasionally regress when immunosuppressive therapy for autoimmune disease is discontinued [24]. However, one review on cytotoxic therapy for rheumatoid arthritis and the subsequent risk of developing lymphoma concluded that the effects were modest at most [25]. A genetic predisposition has also been suggested as a possible factor in the development both of lymphoma and rheumatoid arthritis [26], but as yet there is little evidence to support this idea.

In summary, some pulmonary lymphomas are associated with autoimmune disorders, an association already recognized with lymphomas presenting at several other mucosal sites [27]. These lymphomas are believed to arise from bronchial mucosa-associated lymphoid tissue and its formation and chronic turnover in relation to autoimmune-associated interstitial lung disease may well have a role in the development of lymphoma.

\section{References}

1. L'Hoste RJ Jr, Filippa DA, Lieberman PH, Bretsky S. Primary pulmonary lymphomas: a clinicopathological analysis of 36 cases. Cancer 1984; 54: 1397-1406.

2. Koss MN, Hochholzer L, Nichols PW, Wehunt WD, Lazarus AA. Primary non-Hodgkin's lymphoma and pseudolymphoma of lung: a study of 161 patients. Hum Pathol 1983; 14: 1024-1038.

3. Turner RR, Colby TV, Dogget RS. Well-differentiated lymphocytic lymphoma: a study of 47 patients with primary manifestation in the lung. Cancer 1984; 54: 2088 2096.

4. Kennedy JL, Nathwani BN, Burke JS, Hill LR, Rappaport H. Pulmonary lymphomas and other pulmonary lymphoid lesions: a clinicopathologic and immunologic study of 64 patients. Cancer 1985; 56: 539-552.

5. Addis BJ, Hyjek E, Isaacson PG. Primary pulmonary lymphoma: a reappraisal of its histogenesis and its relationship to pseudolymphoma and lymphoid interstitial pneumonia. Histopathology 1988; 13: 1-17.

6. Li G, Hansmann ML, Zwingers T, Lennert K. Primary lymphomas of the lung: morphological, immunohistochemical and clinical features. Histopathology 1990; 16: 519-531.

7. Cordier JF, Chailleux E, Lauque D, et al. Primary pulmonary lymphomas: a clinical study of 70 cases in nonimmunocompromised patients. Chest 1993; 103: 201-208.

8. Fiche M, Capron F, Berger F, et al. Primary pulmonary non-Hodgkin's lymphomas. Histopathology 1995; 26: 529-537.

9. Nicholson AG, Wotherspoon AC, Diss TC, et al. Pulmonary B-cell non-Hodgkin's lymphomas: the value of immunohistochemistry and gene analysis in diagnosis. Histopathology 1995; 26: 395-404.

10. Isaacson P, Wright DH. Malignant lymphoma of mucosaassociated lymphoid tissue: a distinctive type of B-cell lymphoma. Cancer 1983; 52: 1410-1416.

11. Wotherspoon AC, Ortiz-Hidalgo C, Falzon MR, Isaacson PG. Helicobacter pylori associated gastritis and primary B-cell gastric lymphoma. Lancet 1991; 338: 1175-1176.

12. Gould SJ, Isaacson PG. Bronchus-associated lymphoid tissue (BALT) in human fetal and infant lung. J Pathol 1993; 169: 229-234.

13. Holt PG. Development of bronchus-associated lymphoid tissue (BALT) in human lung disease: a normal host defence mechanism awaiting therapeutic exploitation? Thorax 1993; 48: 1097-1098.

14. Richmond I, Pritchard GE, Ashcroft T, Avery A, Corris PA, Walters EH. Bronchus-associated lymphoid tissue (BALT) in human lung: its distribution in smokers and nonsmokers. Thorax 1993; 48: 1130-1134.

15. Pabst R. Is BALT a major component of the human lung immune system? Immunol Today 1992; 13: 119-122.

16. Hall PA, Jass JR, Levison DA, et al. Classification of primary gut lymphomas. Lancet 1988; ii: 958.

17. Isaacson PG. Lymphomas of mucosa-associated lymphoid tissue (MALT). Histopathology 1990; 16: 617619.

18. Kamel OW, van de Rijn M, Le Brun DP, Weiss LM, Warnke RA, Dorfman RF. Lymphoid neoplasms in patients with rheumatoid arthritis and dermatomyositis; frequency of Epstein-Barr virus and other features associated with immunosuppression. Human Pathol 1994; 1994; 25: 638-643.

19. Symmons DP. Neoplasms of the immune system in rheumatoid arthritis. Am J Med 1985; 78 (1A): 22-28. 
20. Kradin RL, Young RH, Kradin LA, Mark EJ. Immunoblastic lymphoma arising in chronic lymphoid hyperplasia of the pulmonary interstitium. Cancer 1982; 50: 1339-1343.

21. Koss MN, Hochholzer L, Langloss JM, Wehunt WD, Lazarus AA. Lymphoid interstitial pneumonia: clinicopathological and immunopathological findings in 18 cases. Pathology 1987; 19: 178-185.

22. Silman AJ, Petrie J, Hazleman B, Evans SJ. Lymphoproliferative cancer and other malignancy in patients with rheumatoid arthritis treated with azathioprine: a 20 year follow-up study. Ann Rheum Dis 1988; 47: 988 992.
23. Krinlen LJ. Neoplastic disease in rheumatoid disease. Am J Med 1995; 78 (1A): 44-49.

24. Kamel OW, van de Rijn M, Weiss LM. Reversible lymphomas associated with Epstein-Barr virus occurring during methotrexate therapy for rheumatoid arthritis and dermatomyositis. N Engl J Med 1993; 328: 1317-1321.

25. Frizzera G. Immunosuppression, autoimmunity and lymphoproliferative disorders. Human Pathol 1994; 25: 627-629.

26. Bullock M. On the origins of lymphoid neoplasms in rheumatoid arthritis. Hum Pathol 1995; 25: 244-245.

27. Isaacson PG, Spencer J. Malignant lymphoma and autoimmune disease. Histopathology 1993; 22: 509-510. 